\title{
Accidentabilidad vial: muertes por sucesos de tránsito. Morgue Central de Lima, julio a setiembre 2011
}

\author{
Rosángela Vargas, Karina Pariona, Mario Castro, Jessica Santillán, Rosa Carrera, \\ Shérmany Aronés \\ Instituto de Medicina Legal, Ministerio Público, e Instituto de Patología, UNMSM
}

Introducción: Los sucesos de tránsito constituyen un problema de salud pública; comprenden fases y signos para correlacionar lesiones de víctimas con daños del vehículo.

Objetivos: Determinar la incidencia de muertes y signos que diferencian modalidades de sucesos de tránsito.

Diseño: Descriptivo, retrospectivo, transversal.

Institución: Instituto de Medicina Legal, Ministerio Público, e Instituto de Patología, UNMSM.

Material de estudio: Informes periciales, necropsias médico legales.

Intervenciones: Se revisó protocolos de necropsias, seleccionando información de oficio de internamiento, levantamiento de cadáver, exámenes auxiliares.

Principales medidas de resultados: Medidas de tendencia central porcentual.

Resultados: De 1124 autopsias, analizamos 121 por suceso de tránsito. Incidencia en >60 años 28\% (40), masculino $75,2 \%$ (91), modalidad atropello 78,5\% (95), atípico 90,1\% (109); 29,8\% (36) >3 segmentos corporales; alcoholemia 26,4\% (32), 84,4\% (27) alcohol etílico >1 g/L (multiplica por 7 el riesgo de suceso de tránsito); escoriación apergaminada estriada (patognomónica de atropello típico) 17,3\% (21), no descrita 82,7\% (100); no acta de levantamiento de cadáver 0,8\% (1), sí acta fiscal-médico legal 66,9\% (81), por PNP 32,3\% (39) (UIAT).

Conclusiones: El trabajo en equipo fiscal, médico legal y PNP solo se efectuó en 2/3 de casos. La mayor frecuencia se presentó en los grupos etarios de 20 a 50 años, en 48,7\%.

Palabras clave: Accidentabilidad vial, suceso de tránsito.

\section{Evaluación del estado nutricional y su relación con los hábitos alimentarios y actividad física en estudiantes de la I.E. $\mathbf{N}^{\circ} 1168$ Héroes del Cenepa, Lima 2011}

Elsy Mini, Luis Rojas, Ana Ávila, Verónica Bedoya, Marcel Casasola, Roniel Contreras, Abraham Herquinio, Jesús Marcelo, Marco Méndez, Gustavo Salazar

Facultad Medicina, UNMSM, e Instituto Nacional Materno Perinatal

Objetivos: Determinar el estado nutricional y su relación con los hábitos alimentarios y la actividad física en los estudiantes de la I.E.N 1168 "Héroes del Cenepa".

Diseño: Estudio analítico, transversal.

Institución: Facultad Medicina, UNMSM, e Instituto Nacional Materno Perinatal.

Participantes: Estudiantes de tercero, cuarto y quinto de secundaria.

Intervenciones: En una muestra de 192 estudiantes, de ambos sexos, del I. E. Héroes del Cenepa, Cercado de Lima, se realizó prueba piloto para validación de instrumentos. La recolección datos fue con cuestionario autodesarrollado sobre valoración del estado nutricional, con medición de peso y talla, IMC e índice cintura cadera (ICC).

Principales medidas de resultados: Determinación del estado nutricional, hábitos alimentarios y actividad física.

Resultados: El 34\% de estudiantes tenía estado nutricional normal. El 25\% presentó trastornos nutricionales: 18\% sobrepeso y $7 \%$ obesidad. El $58 \%$ de estudiantes con riesgo de sobrepeso y obesidad era varón, $42 \%$ mujer. El $34 \%$ presentó hábitos alimentarios adecuados y $66 \%$ deficientes. El $78 \%$ tenía actividad física vigorosa y $6 \%$ sedentaria.

Conclusiones: No se encontró relación entre el estado nutricional (IMC e ICC) con la actividad física y hábitos alimentarios. Es necesario mejorar los hábitos alimentarios en los estudiantes y explorar otros factores determinantes de la obesidad y sobrepeso en adolecentes.

Palabras clave: Obesidad, sobrepeso, actividad física, hábitos alimentarios, adolescente. 